\title{
DOCUMENTOS CURRICULARES E AS FLEXIBILIZAÇÕES: Escrita histórico-social do currículo em educação especial
}

Fabiany de Cássia Tavares Silva ${ }^{(*)}$

\begin{abstract}
A análise dos discursos implica o questionamento do conhecimento, poder e identidade como espaços de construção, onde a produção dos discursos reflete quer as desigualdades existentes, quer os espaços de contestação, pois "a escola continua a ser um espaço de conflito social. O currículo é lugar, espaço, território. O currículo é uma relação de poder. O currículo é trajetória, percurso. O currículo é autobiografia, a nossa vida, o curriculum vitae: no currículo forja-se a nossa identidade. O currículo é texto, discurso, documento. O currículo é documento de identidades (SILVA, 2003).
\end{abstract}

\section{SITUANDO O OBJETO E OS FUNDAMENTOS DE ANÁLISE}

Os documentos curriculares sistematizam o que está estabelecido na Lei de Diretrizes e Bases da Educação Nacional (LDB, Lei 9.394/96), sobretudo o art. 26 - que incrementam as atuais Diretrizes Curriculares Nacionais para a Educação Básica e outros marcos legais, que regem o sistema educacional do Brasil.

Regência essa determinada pelo processo de produção e divulgação dos documentos curriculares, como estratégia de normalização dos diferentes graus de ensino, o que os torna um dos privilegiados instrumentos de exercício do controle do Estado, ou uma forma de intervenção, fortemente ligada à avaliação e hierarquização das instituições:

O cumprimento das diretrizes curriculares passa a ser então objeto de verificação e essa condiciona a atuação do estado no sistema educacional, uma atuação balizada não pela intervenção no sentido de construção de uma escola de qualidade, mas pela certificação dos estabelecimentos que permitiria aos "consumidores" com maiores possibilidades de escolha a aquisição de um bem melhor. Nesse sentido, a associação entre Estado e cidadão é substituída pela lógica que gere as relações entre prestador de serviços e consumidor e a estratificação das opções é garantida e informada pelo próprio Estado. (MACEDO, 2000, p. 10, grifo no original).

\footnotetext{
${ }^{(*)}$ Doutora em Educação. Programa de Pós-graduação em Educação (UFMS). Pós-doutorado em Educação pela UNIFESP. Bolsista Produtividade CNPq. E-mail: fabiany@uol.com.br.
} 
Tal lógica ancora-se no pressuposto de que as políticas curriculares, que estiveram no centro das reformas educacionais desencadeadas desde os anos de 1990, atenderam ao fenômeno dos:

curricula prescritos centralmente, com metas de desempenho detalhadas e com prazos-limite curtos para a sua concretização, com avaliações associadas a essas metas e com uma prestação de contas que tem sérias consequências, definiram, em todo o Mundo, uma "nova ortodoxia" da reforma educativa - oferecendo soluções estandardizadas e a baixo custo a um eleitorado ávido de prestação de contas. (HARGREAVES, 2003, p. 112).

As soluções encontram nos documentos curriculares, produzidos em âmbito nacional, Parâmetros Curriculares Nacionais para o Ensino Fundamental (PCN), Referencial Curricular Nacional para a Educação Infantil (RCNEI) e Diretrizes Curriculares Nacionais (DCN), ${ }^{1}$ propostas capazes de produzir intersecções entre as questões macro, ligadas ao Estado (políticas de governo, políticas de Estado, expressões de reformas de Estados, entre outros) e, micro, na efetivação da distribuição de conhecimentos articuladas pelo trabalho pedagógico e a atividade docente. ${ }^{2}$

Destacamos que essas intersecções, além de sustentarem as proposições para a Escola Básica, se matizam a partir de contornos específicos do desenvolvimento curricular, identificados no tripé escola, conhecimento e avaliação, alvo das reformulações consideradas necessárias.

As reformulações necessárias são parte da premissa de que os governos nacionais apreenderam rapidamente, que um novo projeto de Nação, inaugurado pós Declaração de Jontiem (1990), devia ter a escola como foco central. Daí, para o encontro da ideologia ${ }^{3}$ neoliberal, como aparato ideológico para legitimar projeto de formação escolar específico, leia-se com "outro" currículo, passa a ser o caminho a trilhar-se. Neste sentido, a ideologia neoliberal influencia a

[...] economia, governo e, indiretamente, educação. [...] a economia deveria ser deixada para o mercado e os governos deveriam desistir de tentar ter políticas econômicas ou industriais. [...] Enquanto delegavam ao mercado livre qualquer papel na economia (com exceção do controle das taxas de juros), os governos dedicavam seus esforços a reformar o sistema escolar ou aprimorar o ‘capital humano'. (YOUNG, 2007, p. 1290).

O sistema escolar torna-se, desta maneira, um bem privado, dotado de valor de troca, situado fora do campo educativo, trocado por emprego, prestígio e conforto. O que per se configura outra

\footnotetext{
${ }^{1}$ Trabalhamos, particularmente, com as Diretrizes Gerais do ano de 2010.

2 Entendemos que a publicação destes documentos assume extrema relevância, na organização dos processos de escolarização e escolaridade de parcela significativa da população brasileira, essencialmente no plano discursivo.

3 “"...] visão de mundo ou perspectiva geral característica de uma classe ou grupo social, a qual inclui crenças formais e conscientes, mas também atitudes, hábitos e sentimentos menos conscientes e menos articulados ou, até mesmo, pressupostos, posturas e compromissos inconscientes" (WILLIAMS, 1992, p. 26).
} 
faceta das políticas neoliberais, centrada na ideia de descentralização. Para Pacheco (2000, p. 145), a origem das políticas de descentralização está nos imperativos da eficácia, de participação nas decisões, de transparência dos serviços, de delimitação de funções, de reconhecimento das realidades locais, conjugados com a necessidade do redimensionamento do papel do Estado. Contraditoriamente,

...embora algumas atribuições do estado sejam realmente despejadas em cima das comunidades locais, outros aspectos do controle estatal são intensificados e tornam-se mais fortes ainda, principalmente seu controle sobre o saber e os valores nas escolas e sobre os mecanismos de avaliação do sucesso ou fracasso institucional nessa reprodução cultural. (APPLE, 2003, p. 36).

Neste contexto, destacamos que para efeito de nossos estudos e análises, escolhemos como documentos curriculares, aqueles produzidos, particularmente, para a modalidade Educação Especial, que coloca em foco a discussão sobre o processo de escolarização deste alunado na chamada escola inclusiva.

Vale destacar, que a Educação Especial, como integrante de sistemas educacionais, torna-se uma modalidade de educação, que deve compartilhar os mesmos pressupostos teóricos e metodológicos presentes nas diferentes disciplinas dos demais níveis e modalidades de ensino.

Como modalidade, a educação especial inaugura um novo contrato educativo, que coloca em discussão não apenas a acessibilidade pedagógica para todos, que independe das premissas da discriminação na escola, e, sim, assume propostas práticas de "inclusão a todos". Práticas essas, no âmbito da escola regular, ofertada por recursos e serviços de apoio pedagógico especializados, que complementam e/ou suplementam a escolarização formal do alunado com deficiência.

Diante disso, temos como fontes de análise, a saber: Referencial sobre Avaliação da Aprendizagem na área da Deficiência Intelectual (SÃO PAULO, 2008) - elaborado pela Secretaria Municipal de Educação de São Paulo, por meio da Diretoria de Orientação Técnica - Educação Especial, por professores do Grupo de Trabalho do Ciclo II, EJA/Cieja e especialistas em Deficiência Intelectual dos Centros de Formação e Acompanhamento à Inclusão (Cefai), das Diretorias Regionais de Educação; Currículo em Movimento da Educação Básica, Educação Especial (BRASÍLIA 2012) - documento, que se propõe a discutir as possibilidades inclusivas tomando por orientação o acesso ao currículo para estudantes com deficiência, transtorno global de desenvolvimento, altas habilidades/superdotação, por meio do currículo funcional e classificação internacional de funcionalidade, incapacidade e saúde; Diretrizes Curriculares para a Educação Municipal - EDUCAÇÃO ESPECIAL (SANTA MARIA, RS, 2008) - apresentada como políticas 
públicas e orientações para o sistema de ensino constituir uma educação de qualidade para todos os alunos. Nesta perspectiva pretende contribuir para as escolas esclarecerem, subsidiarem e acompanharem o processo de aprendizagem e desenvolvimento dos alunos em todos os níveis, de acordo com suas peculiaridades, tendo como princípio básico o respeito à diversidade e; Diretrizes da Educação Especial para a Construção de Currículos Inclusivos (PARANÁ, 2006) - fruto de uma construção coletiva que sistematiza ideias e práticas dos professores e professoras que nas salas de aula de escolas especiais e de escolas regulares, nos Núcleos Regionais de Educação e no Departamento de Educação Especial, apresentando, também, os fundamentos filosóficos, teóricos e legais da Educação Especial no Paraná, contextualizados na complexa dinâmica dos movimentos sociais que inspiraram suas ações em nível nacional e internacional, os quais lhe imprimem um novo sentido na atualidade.

A organização sistemática dessas fontes possibilita-nos a análise das influências e desdobramentos das discussões sobre escolarização do alunado da educação especial, como parte da illusio $^{4}$ do campo educacional, na qual as flexibilizações são consideradas instrumentos para profundas mudanças no espaço escolar inclusivo.

\section{FLEXIBILIZAÇÕES NA ESCRITA HISTÓRICO-SOCIAL DO CURRÍCULO EM EDUCAÇÃO EŞPECIAL}

As flexibilizações curriculares, nos limites de nossas análises, são tomadas como princípio explicativo da discussão curricular na modalidade Educação Especial, delineado por proposições de autonomia, de participação local e de diversidade curricular. A autonomia ancorada na necessidade de um projeto educativo, que responda às necessidades locais, que considere as características da população de uma dada escola e do meio onde ela se situa, bem como os recursos de que dispõe, ou não, de forma a construir uma escola de qualidade. A participação local situada na crença na operação, por parte dos agentes escolares, de um ensino gerador de aprendizagens mais significativas, portanto, como configuradores do currículo e não meros consumidores das prescrições. A diversidade curricular advogada na inadequação de um currículo centralizado e igual, considerando que não é possível criar as mesmas condições de sucesso para alunos dispares entre si.

\footnotetext{
${ }^{4}$ Reconhecimento do jogo e da utilidade do jogo fornece a base para todas as atribuições de sentido e de valor particulares. "O que é vivido como evidência na illusio parece ilusório para quem não participa dessa evidência". (BOURDIEU, 2006, p. 142).
} 
Flexibilizar o currículo significa "deslocar e diversificar os centros de decisão curricular e, por isso, visibilizar níveis de gestão que tinham pouca relevância” (ROLDÃO, 2000, p. 86). Dito de outro modo, analisar as situações, tomar decisões e agir em conformidade com essas decisões e com as leituras que essa ação produz. Para tanto, é imprescindível a criação de um ambiente de aprendizagem, em que cada aluno se sinta partícipe e representado, e no qual encontre condições para organizar os conhecimentos, decorrentes da sua experiência de vida, e adquira aqueles relacionados às experiências de outros, princípios que orientam uma educação, que responda à diferença.

Consideramos a escrita histórico-social do currículo, a partir destes documentos curriculares, privilegiando a análise sobre as propostas para constituição dos processos de escolaridade e os mecanismos de distribuição de conhecimentos em sua complexidade social, epistemológica e ideológica. E neste contexto, a escrita histórico-social do currículo passa a ser tomada como parte de um universo discursivo que existe, conforme Peters (2006, p. 53-54), sob duas formas necessariamente articuladas:

a) como um espaço objetivamente estruturado de relações entre agentes diferenciadamente posicionados segundo uma distribuição desigual de recursos materiais e simbólicos, isto é, de capitais múltiplos que operam como meios socialmente eficientes na concorrência pela apropriação de bens materiais e ideais escassos, ainda que bastante diversificados nos casos das sociedades altamente diferenciadas em diversos "campos" de atividade que caracterizam o Ocidente moderno;

B) como um conjunto de esquemas simbólicos subjetivamente internalizados (via socialização) de geração e organização da atividade prática mental e corporal dos agentes individuais, esquemas que tomam a forma de disposições ou modos potenciais socialmente adquiridos e tacitamente ativados de agir, pensar, sentir, perceber, interpretar, classificar e avaliar.

No processo de objetivação de tal escrita, a compreensão buscada funda-se, necessariamente, na inserção em um espaço de análise mais abrangente para o qual problemas diferentes, em diferentes localidades, possam ter respostas semelhantes ao nível dos objetos investigados, e que são as respostas semelhantes, que encobrem ou dificultam a compreensão das especificidades dos projetos educativos.

Para tanto, operamos com um exercício de comparação nas análises das fontes eleitas, tendo como condição primeira, o reconhecimento da indissolúvel individualidade do outro, para o que Nóvoa (1998) afirma: “a comparação em educação é uma história de sentidos e não um arranjo 
sistematizado de fatos: os sentidos que as diferentes comunidades dão às suas ações e que lhes permitem construir e reconstruir o mundo" (p. 83).

As práticas de pesquisa com o estudo comparado, que intentamos materializar, visam dar atenção às condições e as táticas (no sentido apresentado por Certeau, ${ }^{5}$ 1994) na condução de operações de construção de sentidos. O que significa que não são apenas tradução da materialidade dos instrumentos eleitos e, sim, buscam nos mercados simbólicos que os descrevem, interpretam e localizam uma "retórica de legitimidade".

Dessa forma, é possível que o currículo praticado reproduza e produza usos e significados desligados das intenções curriculares explícitas pela incorporação de práticas sociais, políticas, econômicas, didáticas e escolares de relação entre os indivíduos, de difusão do conhecimento escolar e de controle das aprendizagens, que operam de forma singular.

\section{OS DOCUMENTOS CURRICULARES E AS FLEXIBILIZAÇÕES: EXERCÍCIO DE COMPARAÇÃO POR UMA ESCRITA HISTÓRICO-SOCIAL}

À procura por inteligibilidades do estudo comparado, aqui, assenta-se no cruzamento da educação comparada e a história-social, no esforço de organizar uma abordagem comparativa baseada em fundamentos investigativos que representem, segundo Schriewer (1992), o melhor instrumento para a separação analítica entre o geral e o particular, necessária a uma interpretação histórico-social portadora de sentido.

Para tanto, elegemos áreas de comparação, pelo tripé que ancorou as discussões curriculares de finais da década de 1990, intimamente ligadas com o movimento de investigação destes documentos curriculares, que materializam prescrições, seguidas de orientações pedagógicas.

No que tange as discussões sobre a escola, desenvolvida no âmbito das políticas educacionais da década de 1990 e, particularmente, as curriculares, são tecidas em aproximações às microrrealidades, que se transformam em macro conclusões. As microrrealidades, no âmbito das prescrições, chegam a construir macro conclusões, isto é, como se produz os resultados e adequa-se às realidades como resposta às demandas sociais.

A chamada escola inclusiva, espaço privilegiado das discussões sobre o processo de escolarização dos sujeitos com deficiência, advoga que o sistema escolar tem mais ou menos certo

\footnotetext{
5 “(...) que subverte dispositivos de modelização (...) põe em cena o hiato entre os usos e as prescrições” (CERTEAU, 1994, p. 36).
} 
um ideal de igualdade de oportunidade, mas não tem como se proteger da influência da desigualdade social e econômica nas desigualdades escolares. Assim, a redução das desigualdades sociais segue sendo o meio mais seguro de criar igualdade de oportunidades escolares.

Se, por um lado, a escola comum está muitas vezes insegura ou despreparada para atender aos alunos com necessidades especiais; por outro, a escola especial também necessita rever as concepções e práticas que nortearam suas ações, desde sua origem (PARANÁ, 2006, p. 39).

...escola como espaço privilegiado de saber para a diversidade e para a cidadania, em uma perspectiva de educação para os direitos humanos e, neste sentido, o direito fundamental à educação de qualidade. (BRASÍLIA, 2012, p. 15).

Tal revisão nos limites das "especializações" constitutivas do processo de escolarização dos sujeitos com deficiência, fortalece que a preparação da escola regular

numa perspectiva inclusiva, proporciona um momento diferenciado para a educação brasileira, na medida em que possibilita um processo de criação pedagógica, na busca de novos procedimentos de ensino, novas estratégias metodológicas capazes de atingirem o potencial de cada um dos alunos, respeitando suas diferenças e ao mesmo tempo levando-os a inserção no mundo da cultura e na vivência histórica enquanto homem presente e atuante em seu tempo. (SÃO PAULO, 2008, p. 16).

Essa tomada diferenciada da escola regular dá crédito ao antigo mito dos procedimentos diferenciados reativado junto aos demais que a escola começa a discursar, como o respeito às diferenças, fazendo crer que o sucesso é uma simples questão de esforço pessoal para atuar em um tempo seu. Neste sentido, “A mobilidade dos indivíduos pode concorrer para a conservação dessas relações, garantindo a estabilidade social pela seleção controlada de um número limitado de indivíduos" (BOURDIEU; PASSERON, 1992, p. 176), além disso, eles são modificados pela ascensão individual e confiam na ideologia da mobilidade educativa, na ideologia da escola inclusiva.

Para tanto, esta ideologia está ancorada na necessidade da escola

adaptar-se à diversidade de características, capacidades e motivações de seus alunos, a fim de responder às necessidades educacionais de cada criança, para que todas progridam em sua aprendizagem e participem desse processo em igualdade de condições. (SANTA MARIA, 2008 , snp).

Dessa prescrição depreendemos, que respostas às necessidades educacionais, mesmo que remetidas, discursivamente, ao distanciamento do sentido da reprodução e da legitimação das desigualdades sociais e de aprendizagens, pode estar atraída pela falsa aparência de uma homogeneidade de fachada, para encerrar os sujeitos com deficiência num destino escolar mutilado. 
Mutilação essa alimentada pela ideia de melhoria, de progresso, de "ir além", no sentido de se pensar uma escola que atenda aos sujeitos (pressuposto liberal) na contemporaneidade, sem desconsiderar a diversidade cultural ou o pertencimento dos sujeitos a determinados grupos diferenciados (pressuposto comunitário), como tônica das discussões.

Contudo, tanto os sujeitos, como os grupos diferenciados, necessitam de acesso ao conhecimento, inclusive aqueles "comum a todos", isto é, conhecimentos que em qualquer lugar do país, independente da região, todos devem ter o direito de aprender, cabendo ao Estado assegurar este direito. Mas, mesmo que problematizemos os conhecimentos comuns, em uma perspectiva nacional, ${ }^{6}$ diríamos, que nem esses são considerados nas discussões, uma vez que as premissas se aproximam da parte diversificada a fim de contemplar as especificidades dos planos dos estabelecimentos de ensino e as diferenças individuais dos alunos, bem como a autonomia de professores e equipes pedagógicas.

Segundo Candau e Moreira (2007) os conhecimentos escolares são uma construção específica da esfera educativa, produzidos pelo sistema escolar e pelo contexto social mais amplo em meio a relações de poder estabelecidas no aparelho escolar entre esse e a sociedade.

No intuito de esclarecer a "natureza" dos conhecimentos escolares os autores apontam que:

Os conhecimentos escolares provêm de saberes e conhecimentos socialmente produzidos nos chamados "âmbitos de referência dos currículos". [...] (a) às instituições produtoras do conhecimento científico (universidades e centros de pesquisa); (b) ao mundo do trabalho; (c) aos desenvolvimentos tecnológicos; (d) às atividades desportivas e corporais; (e) à produção artística; (f) ao campo da saúde; (g) às formas diversas de exercício da cidadania; (h) aos movimentos sociais. Nesses espaços, produzem-se os diferentes saberes dos quais derivam os conhecimentos escolares. (CANDAU; MOREIRA, 2007, p. 22).

Nesse sentido, singularizar o acesso ao conhecimento às particularidades dos sujeitos com deficiência, nos faz supor que se houvesse uma mínima discussão dos conhecimentos ao invés dos conteúdos curriculares, nos documentos analisados, essa conferiria poder aos que dele se apropriam, possibilitando a ocupação de novas posições no espaço de lutas que habitam.

Espaço esse determinado pela hegemonia das disposições sobre a flexibilização, que se orienta pelos ajustes que o professor precisa operar nos objetivos pedagógicos, investindo mais

\footnotetext{
${ }^{6}$ A política do conhecimento oficial, para Apple (2006, p. 60) exprime o conflito em torno daquilo que alguns tomam simplesmente como descrições neutras do mundo e outros, como concepções de elite que privilegiam determinados grupos e marginalizam outros.
} 
tempo, ou utilizando maior variedade de estratégias, ou a reformulação da sequência de conteúdo, ou ainda, a eliminação de conteúdos secundários.

Diante disso, a percepção para aceitar como mais dotado de valor os conhecimentos curriculares, que mais se aproximam dos ideais fixados pela essencialização da aprendizagem no processo de inclusão escolar.

...o exercício do conhecimento: conhecer suas formas de ser, de se manifestar e de aprender os conteúdos curriculares. Resta-nos um olhar atento e sensível: como educadores que somos, compreender suas particularidades e nos colocar no desafio do ensino. (SÃO PAULO, 2008, p. $11)$.

A observação sistemática do aluno leva ao aperfeiçoamento e à experimentação dos diferentes estilos de ensino, e permite aos profissionais um maior conhecimento sobre a abordagem de uma certa criança ao aprendizado. (SANTA MARIA, 2008, snp).

A relevância dessa leitura de conhecimento está em não a afastar da ideia do conhecimento poderoso, para o qual a discussão curricular deveria enfatizar:

(a) as diferenças entre formas de conhecimento especializado e as relações entre elas;

(b) como esse conhecimento especializado difere do conhecimento que as pessoas adquirem no seu cotidiano;

(c) como o conhecimento especializado e o cotidiano se relacionam entre si e,

(d) como o conhecimento especializado é tratado em termos pedagógicos. Em outras palavras como ele é organizado ao longo do tempo, selecionado e sequenciado para diferentes grupos de alunos. (YOUNG, 2007, p. 1296).

Contudo, o conhecimento poderoso aqui dá lugar a uma proposição restrita de leitura dos conteúdos escolares, delineado pela ideia de que seja apreendido como fim em si mesmo, entendido como meio para o desenvolvimento das capacidades que permitem aos sujeitos produzir bens culturais, sociais e econômicos.

Os conteúdos estão organizados a partir de diferentes áreas do conhecimento, porém articulamse em uma perspectiva de unidade, progressividade e espiralização, vinculados diretamente à função social. Cada área do conhecimento apresenta o desafio de promover a ampliação para aprendizagens contextuais, dialógicas e significativas em que o ponto de partida deve ser orientado por levantamento de conhecimentos prévios do grupo de estudantes com o qual o professor atua. (BRASÍLIA, 2012, p. 11).

Dessa forma, mesmo que o desenho de currículo nacional esteja organizado em disciplinas e centrado nos conteúdos, parece ser a concepção prática que define a proposta de escolarização dos sujeitos com deficiência, uma vez que 
a dimensão das práticas inclusivas (professores e equipe técnico-pedagógica): envolve a organização do processo de aprendizagem, por meio da flexibilização e adaptações curriculares - de conteúdo, métodos, avaliação - de modo a contemplar a participação de todos os alunos, considerando seus conhecimentos prévios, suas necessidades linguísticas diferenciadas e o contexto social. (PARANÁ, 2008, p. 49).

Ressaltamos que:

[...] o estudo do conhecimento educacional é um estudo ideológico, a investigação do que determinados grupos sociais e classes, em determinadas instituições e em determinados momentos históricos, consideram conhecimento legítimo (seja esse conhecimento do tipo lógico, "que", "como" ou "para"). É, mais do que isso, uma forma de investigação orientada criticamente, no sentido que escolhe concentrar-se em como esse conhecimento, de acordo com sua distribuição nas escolas, pode contribuir para um desenvolvimento cognitivo e vocacional que fortaleça ou reforce os arranjos institucionais existentes (e em geral problemáticos) na sociedade. (APPLE, 2006, p. 83, grifos no original).

No caso particular da escolarização dos sujeitos com deficiência, a compreensão do conhecimento parece estar sujeita a uma configuração menos ideológica e, mais ligada às especificidades das áreas de deficiência, ou porque não dizer, de uma leitura de aprendizagem limitada a elas. O que "pode estar" muito mais próximo da interpretação do currículo oculto, que se apresenta com significados principais nos discursos curriculares sobre o currículo oculto, “expectativas não oficiais; resultados de aprendizagens não previstos; mensagens implícitas presentes na estrutura escolar; participação dos alunos" (PACHECO, 2005, p. 58).

Entendemos esses significados assentados nos discursos sobre as aprendizagens dos sujeitos com deficiência, delineados nos documentos curriculares analisados, "há que se considerar o processo de aprendizagem e desenvolvimento em que se encontra o estudante". (BRASÍLIA, 2012, p. 24).

A aprendizagem, desta forma, oferece uma forte classificação entre o conhecimento específico sobre os sujeitos e o conhecimento pedagógico, o que embora determine atenção aos processos de apreensão dos conhecimentos, contraditoriamente, oferta pouca atenção a ser dispensada ao conhecimento científico.

Chamamos de conhecimento pedagógico aquele que esmaece as fronteiras entre o conhecimento escolar e o não-escolar, presentes nos currículos analisados, uma espécie de discussões curriculares planejadas para alunos "menos capazes". O que, de acordo com Forquin (1993), seria uma demarcação mais ou menos rígida entre aquilo que, no contexto da relação 
pedagógica e em matéria de escolha e organização dos conhecimentos a transmitir, obedece ao controle dos professores, ou dos alunos e, aquilo que escapa a esse controle.

Como não operam como um mínimo de "conhecimento oficial", esta demarcação permitenos observar que cada instituição escolar legitima a seleção cultural efetuada para atender aos preceitos da aprendizagem, de uma forma também especial.

É chegada a hora de valorizarmos o seu processo de aprendizagem, valorizando suas ações peculiares, sua forma de aprender e agir, considerando, inclusive, a relação de seus atos e seus conhecimentos com os conteúdos curriculares propostos para o ensino fundamental. (SÃO PAULO, 2008, p. 26).

Os conteúdos elencados em cada etapa da Educação Básica devem também ser previstos para estudantes com deficiência, transtorno global de desenvolvimento e altas habilidades/superdotação. No entanto, há que se considerar o processo de aprendizagem e desenvolvimento em que se encontra o estudante. (BRASÍLIA, 2012, p. 24).

Estas prescrições presentes nos documentos curriculares, mesmo que legitimem o capital cultural de determinado grupo social, selecionando-o, a sua distribuição, corre o risco de ser dar de forma desigual. As interpretações de aprendizagem apresentam uma forma de relação com o que chamamos de "consumo de deficiência", que é determinado por habitus ligados ao desenvolvimento da educação especial e às formas de vida escolar de seu alunado. Esses habitus são determinantes no acesso que os alunos terão à cultura distribuída pelo currículo, ou pela escola:

Com efeito, para que sejam favorecidos os mais favorecidos e desfavorecidos os mais desfavorecidos, é necessário e suficiente que a escola ignore, no âmbito dos conteúdos do ensino que transmite, dos métodos e técnicas de transmissão e dos critérios de avaliação, as desigualdades culturais entre as crianças das diferentes classes sociais. Em outras palavras, tratando todos os educandos, por mais desiguais que sejam eles de fato, como iguais em direitos e em deveres, o sistema escolar é levado a dar sua sanção às desigualdades iniciais diante da cultura. (BOURDIEU, 2008, p. 53).

Neste sentido, sujeitos oriundos de um meio menos favorecido, terão acesso a uma cultura restrita, muitas vezes limitada à seleção feita por suas possibilidades. Este contato restrito com a cultura será determinante no acesso ao conhecimento oferecido pela escola. E, ainda, este conhecimento, passará por um processo de avaliação, que tende a produzir ele mesmo suas normas de produção e os critérios de avaliação de seus produtos, e obedece à lei fundamental da concorrência pelo reconhecimento propriamente cultural concedido pelo grupo de pares que são, ao mesmo tempo, clientes privilegiados e concorrentes. 
A imposição de significados da avaliação nos documentos curriculares obedece às pressões dos diferentes grupos sociais, nos quais o poder de influência varia de acordo com seus capitais.

... a avaliação a ser feita pela instituição escolar que, coletivamente, deve analisar, diante das necessidades dos estudantes, quais ações ou adequações devem ser realizadas na escola para atendê-los adequadamente. Também segue a avaliação das condições da sala de aula, dos recursos e dos materiais disponíveis, uma vez que tudo isto exerce influência significativa na aprendizagem de todos os estudantes e, de forma particular, daqueles com deficiência intelectual. (SÃO PAULO, 2008, p. 52).

Neste contexto, permanece uma pergunta, quais os capitais dos grupos que discutem o processo de avaliação dos sujeitos com deficiência, ancorados nas discussões sobre o currículo oficial? Pois, agora este capital é tomado como fundamento para a arquitetura do desenvolvimento curricular, passando a ser dado como princípio de organização da modalidade na educação básica, resultando no que chamamos de curricularização dos fundamentos, isto é, transformado em princípios norteadores do processo de distribuição de conhecimentos, na perspectiva de uma educação para a democracia, para a cidadania, para a diferença, para equidade, em concordância com ideais da inclusão escolar.

Em verdade, a ênfase destes princípios parece não estar em determinados tipos de conhecimentos, configurados como possíveis respostas às demandas de aprendizagem, mas, sim, na forma como seriam ofertados/apreendidos:

Adaptações relativas à avaliação estão vinculadas às alterações em conteúdos que foram acrescidos ou eliminados, evitando-se assim cobrança de resultados que possam estar além da capacidade do estudante. (BRASÍLIA, 2012, p. 28).

(...) a prática da flexibilização curricular se concretiza na análise da adequação de objetivos propostos, na adoção de metodologias alternativas de ensino, no uso de recursos humanos, técnicos e materiais específicos, no redimensionamento do tempo e espaço escolar, entre outros aspectos. (PARANÁ, 2006, p. 9).

O que, possivelmente, desencadeia um processo de tratamento superficial das condições de empoderamento no/do acesso aos conhecimentos científicos, em nome de uma valorização da engenharia de procedimentos na construção das relações educativas escolares, que partem da prática para a prática. Uma prática, que parece estar fundada na noção de competência na constituição dos comportamentos e valores necessários/requeridos pelo projeto de adaptação e/ou flexibilização. A tomada da noção decorre de escolhas conceituais, a partir de relações de poder em construções discursivas, "[...] o modo como o termo competências está incorporado aos dispositivos normativos evidencia uma linguagem de natureza prescritiva e funcional” (SILVA, 2008, p. 40). 
Natureza essa que afasta a discussão sobre os "conhecimentos poderosos", isto é, assentada na emergência da distribuição de conhecimentos especializados, principalmente aos menos favorecidos, visto que encontram na escola um dos poucos, ou talvez o único, espaço no qual tenham o direito de acessá-los. Conhecimentos para além da vida cotidiana. É “[...] importante dispor de conhecimentos e formas de pensamento que permitam problematizar a prática social com base nos conhecimentos especializados, de forma a aprofundar o entendimento das múltiplas relações envolvidas nos fenômenos naturais e sociais" (GALIAN; LOUZANO, 2014, p. 1112).

O eixo central da discussão das flexibilizações é deslocado da seleção e distribuição de conhecimentos para o desenvolvimento de competências e habilidades requeridas tanto do professor quanto do aluno. Assim, os conhecimentos passam a ter tratamento secundário no processo de escolaridade, sendo-lhes atribuído um sentido bastante utilitarista, em caráter produtivo.

\section{PELOS SENTIDOS DA COMPARAÇÃO}

Na elaboração dos documentos curriculares, em que pese os anos de produção, há uma prerrogativa jurídica fundada no direito à educação, inserido desde as reformas educativas de finais da década de 1990. Os parâmetros, referenciais e diretrizes publicados previam que a distribuição de conhecimento se efetivaria, de fato, com os documentos produzidos pelas Redes de Ensino, as quais assegurariam as particularidades locais.

Neste cenário, os discursos dos documentos curriculares analisados, publicados em diferentes locais do País, assentaram-se na perspectiva inovadora de "funcionalizar" a Escola Básica, assegurando a "qualidade" dos processos de seleção e distribuição de conhecimentos, avaliados para consolidar, a eficácia dessa escola, também, reconhecida como inclusiva.

Dentro dessa fórmula, tomaram o currículo como instrumento facilitador do processo de escolarização dos sujeitos com deficiência, prevendo o mesmo resultado orientador das reformas curriculares para a educação básica, isto é, “educação como resultado”. Nessa previsão, o ensino e o aprendizado são dominados pela definição, da educação não mais como mera transmissão de conhecimento em diferentes áreas específicas, mas com objetivos delineados, também, para os sujeitos a serem escolarizados.

Contraditoriamente, esses documentos curriculares, mesmo apresentando-se como construções discursivas sobre a escola, sobre os processos de escolarização e, especialmente sobre a escolaridade, estão carregados de sentidos instrumental e didático, pensado para cooperar com o 
trabalho de educadores na organização da prática pedagógica em sala de aula. Preocupados com as necessidades da escolarização, as proposições para a escolarização daqueles sujeitos, tornam reducionistas as práticas de flexibilização, incidindo em toda a organização dos processos de acesso ao conhecimento, mas, não sobre quais conhecimentos seriam distribuídos. O que per se não enfrenta concepções, que contrariam a emancipação política e social desses sujeitos.

Por fim, a seleção e distribuição de conhecimentos poderosos, conhecimentos científicos, que promoveriam o empoderamento dos sujeitos, forjando neles mais do que uma consciência sobre si mesmo, mas também uma consciência em si a respeito dos movimentos de organização da sociedade, dão lugar a uma previsão prática de acesso, por inclusão ou supressão de um "desconhecido" conteúdo curricular. 


\section{REFERÊNCIAS}

APPLE, Michael. Ideologia e currículo. Porto Alegre: Artmed, 2006.

Educando à Direita: mercados, padrões, Deus e desigualdade. São Paulo: Cortez, Instituto Paulo Freire, 2003.

BOURDIEU, Pierre. Razões Práticas. São Paulo: Papirus, 2008.

; PASSERON, J-Claude. A reprodução. Rio de Janeiro: Francisco Alves, 1992.

BRASIL. Lei 9.394, de 20 de dezembro de 1996. Estabelece as diretrizes e bases da educação nacional. Diário Oficial da União. Brasília: Poder Legislativo, 23 dez. 1996, sec. I, n. 248, p. 27.833

; MEC/SEE. Parâmetros curriculares nacionais: introdução aos parâmetros curriculares nacionais. Brasília: MEC/SEF, 1997a. 126p.

; MEC. Referencial Curricular Nacional para a Educação Infantil. Brasília: MEC/SEF, 1997b. 126p.

. CNE/CEB. Resolução 04, de 13 jul. 2010. Diretrizes Curriculares Nacionais para a Educação Básica. Diário Oficial da União, Brasília, 14 jul. 2010, Seção 1, p. 824.

BRASíliA. SEE/DF. Currículo em Movimento da Educação Básica. Brasília, DF, 2012. Disp.: <http://www. se.df.gov.br/component/content/article/282-midias/443-curriculoemmovimento.html>. Acesso: 12 ago. 2015.

CANDAU, V.M.; MOREIRA, A.F.B. Indagações sobre Currículo: Currículo, Conhecimento e Cultura. Brasília: MEC/SEB, 2007. Disp.: <http://portal.mec.gov.br/seb/arquivos/pdf/Ensfund/indag3.pdf>. Acesso: 29 jun. 2016.

FORQUIN Jean-Claude. Escola e cultura: as bases sociais e epistemológicas do conhecimento escolar. Porto Alegre: Artes Médicas, 1993.

GALIAN, C.V.A.; LOUZANO, P.B.J. Michael Young e o campo do currículo: da ênfase no "conhecimento dos poderosos" à defesa do "conhecimento poderoso". Educação \& Pesquisa, São Paulo, v. 40, n. 4, p. 1109-1124, out/dez. 2014. Disp.: <http://dx.doi.org/10.1590/S1517-97022014400400201>. Acesso: 9 jun. 2016.

HARGREAVES, Andy. O Ensino na Sociedade de Conhecimento: a educação na era da insegurança. Trad.: Jorge Ávila de Lima. Porto: Porto Editora, 2003. 285 p.

MACEDO, Elizabeth. Formação de professores e diretrizes curriculares nacionais: para onde caminha a educação? In: Revista Teias. Rio de Janeiro: UERJ, vol. 1, n. 2. 2000.

PACHECO, J. A. Políticas curriculares descentralizadas: autonomia ou recentralização? Educação e Sociedade. Revista Quadrimestral de Ciência da Educação. ano XXI, n. 73, dez. 2000. p. 139-161.

PARANÁ. SEE/SE. Diretrizes da Educação Especial para a Construção de Currículos Inclusivos. Curitiba, PR, 2006. Disp.: 〈http://www.diaadiaeducacao.pr.gov.br>. Acesso: 9 jan. 2016.

PETERS, G.M. Percursos na teoria das práticas sociais: Anthony Giddens e Pierre Bourdieu. 2006. 269f. Dissertação (Mestrado em Sociologia) - Universidade de Brasília, Brasília: 2006.

ROLDÃO, M. C. Currículo e Gestão das Aprendizagens: as Palavras e as Práticas. Universidade de Aveiro, 2000.

SANTA MARIA. Prefeitura Municipal de Santa Maria. Secretaria de Município Da Educação. Diretoria de Ensino. Diretrizes Curriculares para a Educação Municipal. Educação Especial. Santa Maria, RS, Mimeo, 2008.

SÃO PAULO. SEC. Referencial sobre Avaliação da Aprendizagem na área da Deficiência Intelectual. São Paulo: SME / DOT, 2008.

SILVA, F.C.T. Dos estudos comparados à escrita histórico-social do currículo: documentos curriculares como fontes. São Paulo: Pesquisa de Pós-doutoramento, Bolsa PDS/CNPq/Unifesp, 2016.

SILVA, M.R. Currículo e competências: a formação administrada. São Paulo: Cortez, 2008. 165p.

SILVA, T.T. Documentos de identidade: uma introdução às teorias do currículo. 2. ed. Belo Horizonte: Autêntica, 2003.

WILLIAMS, Raymond. Cultura. Rio de Janeiro: Editora Paz e Terra. 1992.

YOUNG, M. F. D. Para que servem as escolas? Educação e Sociedade, Campinas, v. 28, n. 101, p. 1287-1302, set./dez. 2007. Disp.: <http://www.cedes.unicamp.br>. Acesso: 19 junho de 2016. 


\section{RESUMO}

Apresentamos aqui, resultados de pesquisa, desenvolvida no pós-doutoramento, que objetivou a escrita histórico-social do currículo em Educação Especial, como integrante de sistemas educacionais, ao tornar-se uma modalidade de educação, que deve compartilhar os mesmos pressupostos teóricos e metodológicos presentes nas diferentes disciplinas dos demais níveis e modalidades de ensino. Para efeito dos estudos e análises, operamos com quatro documentos curriculares, produzidos entre 2006 a 2012, que colocam em foco a discussão sobre o processo de escolarização dos sujeitos com deficiência na chamada escola inclusiva. Operamos com o exercício de comparação, para as análises das fontes eleitas, tendo como condição primeira, o reconhecimento de que a comparação em educação é uma história de sentidos e não um arranjo sistematizado de fatos.

Palavras-chave: Educação Básica; Educação Especial, Currículo, Estudos Comparados.

\section{CURRICULAR DOCUMENTS AND FLEXIBILITIES: SOCIAL-HISTORICAL WRITING CURRICULUM IN SPECIAL EDUCATION}

\section{ABSTRACT}

We present here results of the research, developed in the post-doctorate, that aimed to write the socialhistorical curriculum in special education, as a part of educational systems, by becoming a method of education, it should share the same theoretical and methodological assumptions presented in the different subjects of the other levels and types of schooling. For the studies and analyses, we operate with four curricular documents produced in different states of the country, from 2006 to 2012, which focus on the discussion on the schooling process of the individuals with disabilities in the so-called inclusive school. We operate with the comparison exercise, for the analyses of the elected sources, having as the foremost condition the recognition that the comparison in education is a story of senses and not a systematic arrangement of facts.

Keywords: Basic Education; Special Education; Curriculum; Comparative Studies.

Submetido abril 2016 Aprovado jun. 2016 